\title{
LA VIDA DESPUÉS DE LA DEVASTACIÓN: LO COMÚN DE LA TRAGEDIA EN TERRITORIOS SOCIOBIODIVERSOS DE CHILE Y BRASIL
}

\author{
The Life Beyond the Devastation: the Common of the Tragedy in Social and Biodiverse
} Territories in Chile and Brazil

\section{FRANCISCO ARAOS*, WLADIMIR RIQUELME**, JUAN CARLOS SKEWES***, ANA VIANNA ${ }^{* * * *}$, RICARDO ÁLVAREZ ${ }^{* * * * *}$, FRANCISCO THER ${ }^{\star * * * * *}$,

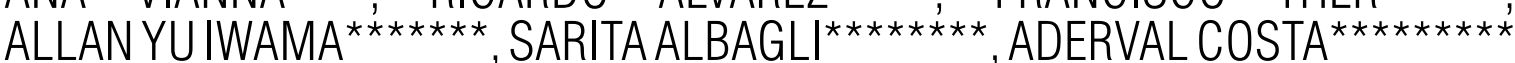 \& EMMANUEL DUARTE ${ }^{\star * * * * * * * \star *}$}

Fecha de recepción: 18 de marzo de 2019 - Fecha de aprobación: 16 de septiembre de 2019

\section{Resumen}

El deterioro de los procesos vitales del planeta producto de las constantes crisis y desastres ambientales nos obliga a repensar la tragedia de los comunes como ejercicios sociopolíticos de regeneración de la vida en territorios devastados. El artículo analiza cuatro casos asociados a la degradación y regeneración de los comunes en Chile y Brasil, revelando que los siniestros normativos anteceden a las catástrofes socioambientales; que el despliegue de las micropolíticas locales contribuyen a la recomposición de lo común, y que la regeneración de la vida se produce por medio de enredos creativos entre humanos y no humanos. Concluimos que el futuro común depende de la renovación ontológica de la vida y de la recomposición de paisajes capaces de hospedar otras formas de vivir con/en/después de la devastación.

Palabras clave: tragedia de los comunes, territorios, Chile, Brasil.

\section{Abstract}

The deterioration of the vital processes of the Planet produced by the environmental crisis and disasters forces us to rethink the tragedy of the commons as socio-political exercises for the regeneration of life. The article analyzes four cases associated with the degradation and regeneration of the commons in Chile and Brazil, revealing that: i. Regulatory claims precede socio-environmental catastrophes; ii. The deployment of local micro-politics contributes to the composition of the commons; iii. The regeneration of life occurs through creative entanglements between humans and non-humans. We conclude that the common future depends on the ontological renovation of life and the recomposition of landscapes with the ability to host other ways of living beyond the devastation.

Keywords: tragedy of the commons, territories, Chile, Brazil.

* Dr. en Ambiente y Sociedad. Académico, Universidad de Los Lagos, Osorno, Chile. Correo-e: francisco.araos@ulagos.cl

** Magíster en Asentamientos Humanos y Medio Ambiente. Investigador independiente, Santiago, Chile.

Correo-e: wladiriquelme@gmail.com

*** Dr. en Antropología. Académico, Universidad Alberto Hurtado, Santiago, Chile. Correo-e: jskewes_cl@yahoo.com

**** Dra. en Ambiente y Sociedad. Académica, Universidad Federal de Minas Gerais, Belo Horizonte, Brasil.

Correo-e: biaviannamendes@gmail.com

**** Antropólogo. Programa ATLAS, Universidad de Los Lagos, Osorno, Chile. Correo-e: taijataf@gmail.com

$\star \star \star \star \star \star$ Dr. en Antropología. Académico, Universidad de Los Lagos, Osorno, Chile. Correo-e: fther@ulagos.cl

$\star * \star * * * \star$ Dr. en Ambiente y Sociedad. Académico, Universidad de Los Lagos, Osorno, Chile. Correo-e: allan.iwama@gmail.com

******* Dra. en Geografía. Instituto Brasileiro de Informação em Ciência e Tecnologia, Río de Janeiro, Brasil.

Correo-e: sarita.albagli@gmail.com

${ }_{\star \star \star \star \star \star \star \star \star}$ Dr. en Antropología Social. Universidade Federal de Minas Gerais, Belo Horizonte, Brasil. Correo-e: adervalcf@gmail.com

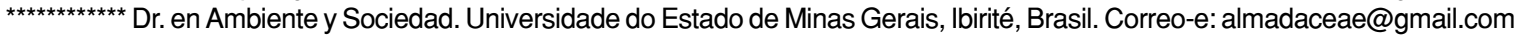




\section{Introducción}

La crisis ambiental global obliga a repensar la tragedia de los comunes como expresión del deterioro de los procesos vitales del planeta y a buscar allí el germen para la regeneración de la vida. En este artículo interesa avanzar en una lectura crítica de una concepción de la relación entre los seres humanos y la naturaleza que ha orientado políticas públicas que, en muchas ocasiones, han protegido más a la propiedad que a la naturaleza. Los comunes son víctima de asedios múltiples y no solo de la voracidad empresarial. También les afectan las visiones unilaterales que se desprenden de una comprensión utilitaria de la naturaleza y de la omisión de prácticas que dan cuenta de fórmulas alternativas de vinculación con el medio ambiente. El giro neoliberal y, en particular, la privatización del individuo y el mito de la perpetua acumulación, como lo sugiere Fleming (2017), subyacen en la acción depredadora que, de otro modo, es atribuida a los actores colectivos, a las comunidades y las personas descritas como oportunistas en el aprovechamiento de aquello que es de todos. Sin embargo, es más bien la economía mundial la que se vuelca "a la búsqueda del lucro antes que, a la satisfacción de necesidades, a la externalización de los costos y a la internalización de los beneficios, y a la privatización de los comunes antes que a la conservación y protección de un bien de todos" (Abaleron, 2010, p. 43).

En 1990, a veintidós años de su formulación, la inspiración original de la "tragedia de los comunes" de Garret Hardin (1968) admitía ya ciertas variaciones que, sin distorsionar su espíritu original, daban cuenta de los múltiples modos como los usuarios de los sistemas naturales han sido capaces de restringir o de regular el acceso a los recursos para su explo- tación sustentable. Esto llevó a plantear una taxonomía de regímenes de propiedad privados, públicos o comunitarios para la administración de esos recursos, tal como lo sugieren Feeny, Berkes, McCay \& Acheson (1990). Los factores culturales e institucionales se incorporan en esta perspectiva para facilitar el análisis de cada situación particular y predecir cuáles pueden ser sus resultados ecológicos. No obstante, estos y otros planteamientos formulados a la tragedia de los comunes reinciden en una comprensión que inevitablemente reduce la naturaleza a la condición de recurso y que apuesta por una búsqueda de sustentabilidad a partir de su gestión económica, tal como ocurre con la propuesta de Elinor Ostrom (2007) acerca de los sistemas socioecológicos y con la perspectiva de los servicios ecosistémicos (Wang y Fu, 2013).

La búsqueda de modos alternativos de comprender las articulaciones entre las poblaciones humanas y no humanas pasa por identificar casos en los que la visión puramente utilitaria se revela insuficiente para dar cuenta de ellos. Para esto, el artículo aborda experiencias locales desarrolladas en territorios sociobiodiversos de Brasil y Chile que ponen de relieve el proceso de articulación entre sociedad y naturaleza en contextos de degradación ambiental. Esta perspectiva -posicionada en el involucramiento práctico y recíproco de actores humanos y no humanos- permite sortear la bifurcación naturaleza/cultura al mismo tiempo que trascender lo utilitario/económico (Viveiros de Castro, 2004; Descola, 2012).

El análisis aquí presentado surge como resultado de una plataforma de debate antropológico a nivel latinoamericano que busca establecer elementos comunes para la comprensión de las dinámicas territoriales de áreas sociobiodiversas $^{1}$, particularmente en regiones con una 
importante presencia de áreas protegidas y poblaciones tradicionales e indígenas.

Los casos que se invita a visitar en este artículo se refieren a: i) sistemas forestales o agroforestales y el uso tradicional del fuego en la zona central de Chile y en el Cerrado brasileño y ii) sistemas marino-costeros y arreglos emergentes para la protección de lugares y modos de vida en la Patagonia norte de Chile y en la Mata Atlántica del sudeste de Brasil. En su conjunto muestran acciones colectivas desplegadas en momentos diferentes de la devastación, ya sea durante la materialización de la crisis y la posterior reorganización socioecológica, o bien como ejercicios de anticipación y/o restauración frente a la degración prolongada de los ecosistemas y los medios de vida de las poblaciones locales.

Respecto de estas situaciones se presentan resultados claves de investigaciones de mayor alcance realizadas por los autores del presente artículo, que han incluido actividades de pesquisa científica, peritaje antropológico y activismo socioambiental. Los casos chilenos forman parte de investigaciones antropológicas desarrolladas entre 2014 y 2017, cuyo punto en común es el interés por las dimensiones humanas de la conservación ambiental. Metodológicamente, se basaron en etnografías llevadas a cabo en las localidades mencionadas, donde se realizaron observaciones participantes y entrevistas en profundidad acerca de los incendios, las creencias religiosas y las actividades productivas (Pumanque), así como de las prácticas de conservación y manejo de recursos naturales de grupos locales, científicos, funcionarios públicos y ONG (Raúl Marín Balmaceda).

Por su parte, los casos brasileños corresponden a trabajos antropológicos de investigación-acción enfocados en el reconocimiento de derechos territoriales a poblaciones tradicionales, realizados entre los años 2015 y 2019. En ambas experiencias actuaron equipos interdisciplinarios y se desarrolló un trabajo etnográfico y cartográfico con comunidades tradicionales. Cada estudio de caso representa, por lo tanto, una investigación con preguntas y fines específicos, pero que revisadas en conjunto entregan luces para comprender el desenvolvimiento de la tragedia de los comunes en territorios sociobiodiversos, así como las articulaciones emergentes de carácter local y regional para salir y superar la tragedia.

La revisión de los casos y su análisis ponen en evidencia que la tragedia de los comunes es atribuible a dimensiones que exceden la pugna por el acceso a los recursos. En este sentido, proponemos desarrollar y discutir tres ejes analíticos que nos permiten avanzar en este punto: i) siniestro normativo: entendido como la imposición de sistemas de normas sobre los bienes comunes que detonan transformaciones profundas en los sistemas locales, que afectan tanto a las poblaciones humanas como al ecosistema; ii) micropolíticas emergentes: referidas a ejercicios locales de control y gobernanza de bienes y espacios comunes; iii) regeneración de la vida: como expresión de la resiliencia de los sistemas socioecológicos que sostienen la diversidad de la vida en los territorios y su recomposición a partir de nuevos arreglos entre humanos y no humanos.

La discusión en torno de estos tres ejes permitirá sostener que la tragedia no radica en la voracidad colectiva por fagocitar el bien común, sino más bien en la descapitalización de la comunidad inducida por el Estado a través de sus intermediarios, en la competencia desmedida de los poderes económicos y en la incomprensión de las dinámicas locales que permiten 
la resurgencia de los procesos vivientes. En este sentido, abogamos por una aproximación a la tragedia de los comunes que, a través del análisis multisituado en territorios sociobiodiversos de América del Sur, logre identificar los elementos comunes a la tragedia (Abaleron, 2010). Eso nos puede permitir aprehender y valorar la autonomía de los procesos locales en los términos que le son propios para su comprensión y en su lectura a través de los procesos vitales resultantes de micropolíticas abiertas a coaliciones heterogéneas en su composición y que incluyen a otros seres más allá de los humanos.
El artículo presenta, a continuación, una aproximación teórica acerca de los recursos comunes y sus intersecciones con el debate en torno a las relaciones entre humanos y no humanos. Sigue una descripción de los estudios de caso seleccionados enfocada en lo común de la tragedia en Chile y Brasil. Luego, profundizamos en cada uno de los ejes utilizando las experiencias descritas para comprender los arreglos y las estrategias que pueden propiciar la vida después de la devastación. Finalmente, en las conclusiones se entregan algunas luces para avanzar hacia nuevas formas de habitar, así como preguntas de investigación que pueden motivar futuras indagaciones.

Imagen 1. Mapa ilustrativo de los casos de estudio analizados.

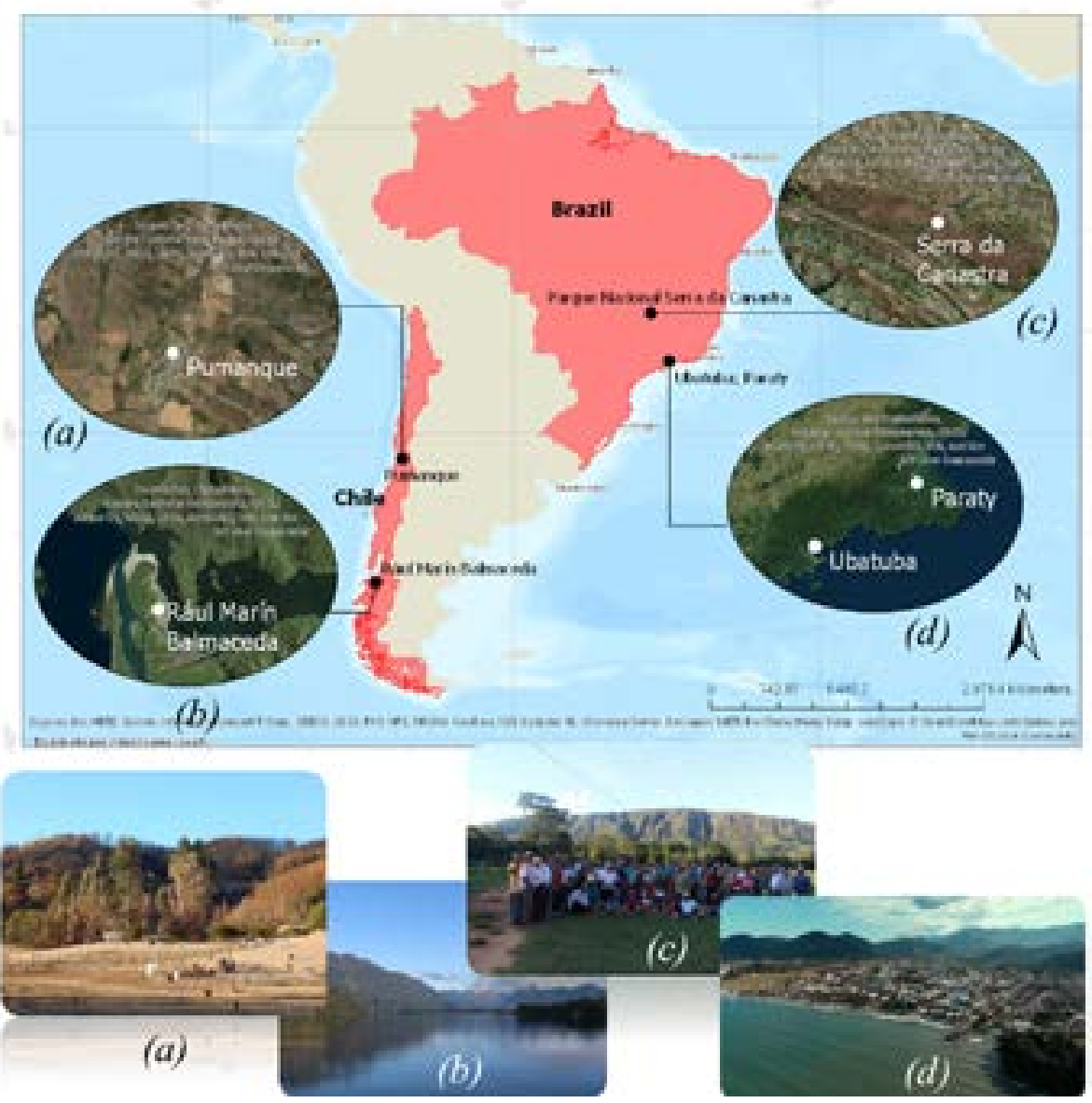

Elaborado por Allan Yu Iwama. 
Miradas antropológicas sobre los comunes: una aproximación teórica

La reflexión acerca de la tragedia de los comunes no es nueva en la antropología. Tempranamente y como respuesta a la propuesta de Garret Hardin (1968), las etnografías no tardaron en demostrar que la profecía no se cumplía y, más importante aún, que los presupuestos de la tragedia de los comunes eran equívocos: ni el individualismo ni el racionalismo maximalista son explicaciones suficientes para informar acerca de los procesos de devastación ecológica (Jack, 1989). No obstante, la lógica sobre la cual se construyó el argumento acerca de los comunes siguió vigente y encuentra reverberaciones tanto en la obra de Elinor Ostrom (1990) como en la de Robert Costanza (2000).

Frente a los planteamientos de Hardin, Ostrom propone, para enfrentar la depredación y la sobreexplotación de los recursos, una solución fundada en la cooperación. En su fórmula, los actores están llamados a convenir en los costos y los beneficios que supone el acceso a los recursos. Para que su fórmula resulte no se requiere ni de un énfasis regulador ni de una privatización de los modos planteados por Hardin. Lo que se impone, en cambio, es un soporte institucional que garantice el cumplimiento de los acuerdos por parte de los distintos participantes. Las relaciones que se generan en la interacción entre los actores se traducen en una red de mutuas dependencias que van tornando imposible desentenderse de los procesos locales.

Mientras Ostrom lleva la solución al campo de los arreglos institucionales, Costanza et al. (1997) lo llevan al de la economía. Su propuesta más radical apunta, justamente, a cuantificar el valor monetario de la riqueza natural y de los costes e impactos que supone su explotación. Llevada la cuantificación a su extremo, en términos de costes y beneficios, el sistema socioecológico alcanzaría su equilibrio.

Tanto Garret Hardin, Robert Costanza y Elinor Ostrom encaran la crisis ambiental desde la perspectiva moderna, que en antropología ha sido profundamente criticada (Latour, 1993; Descola, 2012). La separación de la naturaleza como recurso y su manejo racional, a través de la valoración de sus servicios vía acuerdos suscritos entre partes involucradas, importa la ficción de entender la humanidad como separada de aquello de lo que es parte (Ingold, 2000; Descola \& Pálsson, 2001). La reflexión contemporánea en la disciplina, al reconocer el involucramiento recíproco entre seres humanos y no humanos en la regeneración de la vida, abre paso a nuevos arreglos socioambientales (Viveiros de Castro, 2002; Escobar, 2008; De la Cadena, 2015; Kohn, 2013). La lección, en este sentido, no deviene ni de su carácter racional ni de su afán maximizador. Por el contrario, lo que se pone en juego, por una parte, son concepciones en las que la naturaleza y sus frutos se entienden como la prolongación de la vida de las personas, al mismo tiempo que el mar o el bosque alimentan su ser a través de los humanos con los que se relacionan. $Y$ esto englobado en el principio de incertidumbre e indefinición que marca el curso de estas relaciones.

Frente a un capitalismo que se socava a sí mismo en términos de su sustento físico, es oportuno preguntarse acerca de las alianzas virtuosas que pueden producir la acción combinada de humanos y no humanos en aras de la regeneración de la vida en la incertidumbre (Tsing, 2015). Semejante perspectiva se inscribe en el marco de una antropología de la vida que 
define en términos dialógicos la relación entre las especies (Kohn, 2007), una opción teórico-metodológica que invita a observar ya no como los humanos representan y usan a la naturaleza y a los otros seres vivos, sino a las interacciones y las asociaciones que componen el mundo creado en el devenir conjunto de los seres que habitan el planeta. Nos referimos, por lo tanto, a arreglos socioambientales que expresan ontologías en movimiento, en los que la vida y los procesos vitales se constituyen como extensión de relaciones recíprocas entre los seres (Kohn, 2015; Povinelli, 2014).

Las propuestas que se plantean aquí intentan visibilizar y valorar los atisbos de un nuevo horizonte de sustentabilidad que emergen de las dialécticas y las dialógicas locales entre seres humanos y no humanos (Blaser, 2009; Escobar, 2012). Es lo que explica que en áreas de profunda devastación, como las descritas por Tsing (2015) o las detectadas durante los catastróficos incendios forestales ocurridos en Chile en el verano de 2017, comienzan a reagruparse las comunidades de recolectores de hongos y a reaparecer los hongos mismos, que crecen entre los árboles quemados y las cenizas de la región del Maule, en el centro sur del país.

Para abordar los casos aquí discutidos apostamos por incorporar la unidad biocultural que condiciona la resiliencia de los organismos vivos, humanos incluidos (Rozzi et al., 2010). En oposición a los cálculos de costes, lo que aquí se propone es entender los procesos ambientales como un producto en permanente remodelación a partir de la acción combinada y la dialéctica que se da entre sus diversos componentes. A la racionalidad se opone, en este sentido, la pertinencia: aquello que sostiene la vida es fruto inequívoco de las pequeñas virtu- des y las capacidades que múltiples actores han tenido para adecuarse recíprocamente. Semejante acomodo está marcado por las convergencias en las trayectorias de vida de las múltiples especies que concurren a la formación de un determinado paisaje -siempre evanescente- y cuya existencia es vinculante (Ingold, 2013; Massey, 2005). La configuración de tales paisajes se corresponde, como Basso (1996) argumenta, con una historicidad creada y recreada a través de sucesivas generaciones, que van sedimentando patrones de interacción sujetos a los desafíos que las situaciones emergentes imponen.

\section{Lo común de la tragedia en Chile y Brasil}

Arreando el fuego por los rincones de Pumanque, Chile

La localidad rural de Pumanque se encuentra en uno de los valles transversales de la cordillera de la Costa. Esta última se caracteriza por tener vegetación esclerófila y por ser uno de los hotspot relevantes para la conservación de la biodiversidad a nivel global (Arroyo et al., 2008). Se encuentra intervenida por quebradas con sitios de significación religiosa y montes con abundantes plantaciones forestales (Moraga, 2012).

Durante el verano del año 2017 ocurrieron en esta región grandes incendios forestales que le valieron la denominación de tormenta de fuego ${ }^{2}$ por parte de las autoridades gubernamentales. La metáfora de la tormenta daba cuenta de la incapacidad de los bomberos y los funcionarios públicos para contener las llamas y de su voracidad y salvajismo como efecto de una naturaleza desbocada. 
A pesar de la fuerza de esta visión pública -y publicitaria- de los incendios, la experiencia local de combate a las llamas dio cuenta de una relación diferente con el fuego. Los habitantes de Pumanque señalan que este fue alejado por su acción, que, como una bestia animal que deambulaba sin rumbo por los rincones de la localidad, fue arreado hacia los montes y quebradas con plantaciones forestales, lejos de las casas y los cultivos. El fuego es percibido como un animal salvaje que puede ser domesticado. Al respecto, un campesino señala:

Andaba encarneado ese fuego, en olitas de un kilómetro para arriba, a mitad de la loma, jdelgadito! Lo arreamos a caballo y unos azotes hasta la quebrada y ahí la bomba lo apagó. También lo encontramos en el pasto corto, los bomberos nos dijeron que por ahí no pasaría, y qué, les dije que por ahí pasaría más rápido que en el monte. Así fue, no había caso. Los de la CONAF muy echaditos debajo de los quillayes y el fuego bien mañoso corriendo por los montes. Si no conociéramos estos cerros, muy quemado aquí estaría.

Los campesinos conocían el camino del fuego y la manera en que debía ser arreado hacia sectores descampados para ser apagado. Estos conocimientos, sin embargo, fueron escasamente utilizados en el combate al fuego, dada la visión puramente técnica y gubernamental desplegada en la tragedia.

Imagen 2. Árbol nativo "sobreviviente". Imágenes registradas en febrero y septiembre de 2017.
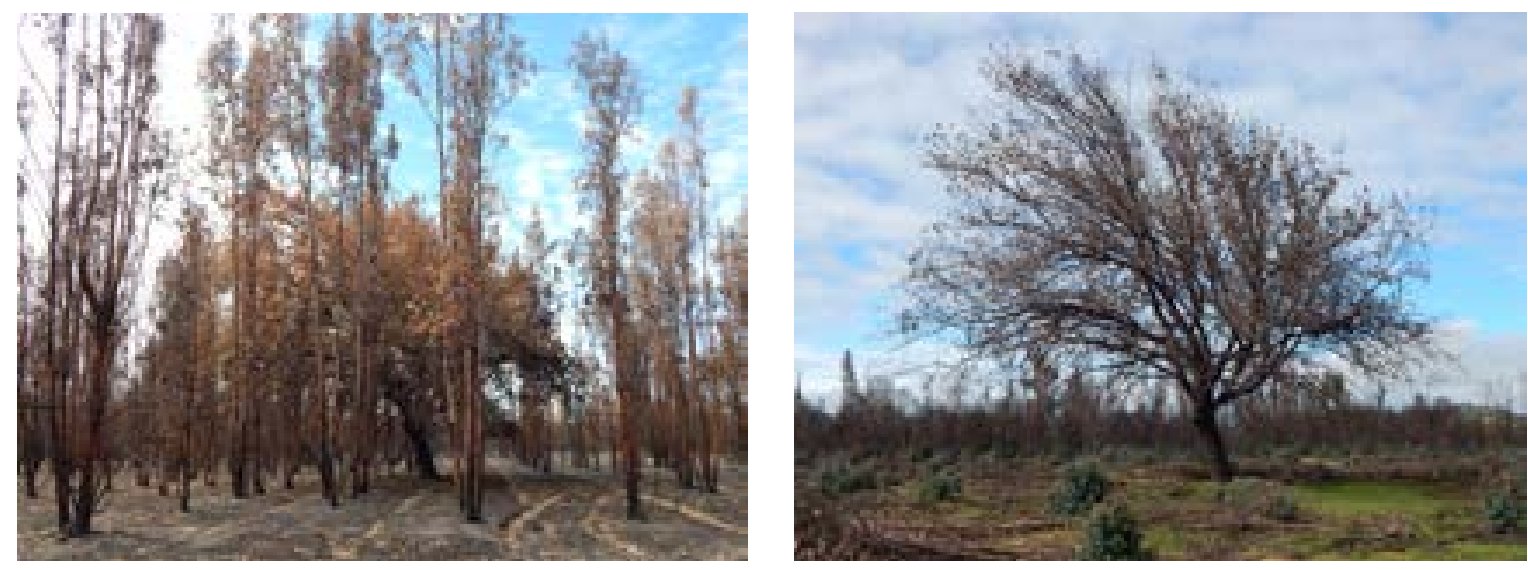

Fotografías: Wladimir Riquelme.

Razones en llamas: manejo del fuego y la creación del Parque Nacional Serra da Canastra, Brasil

El manejo del fuego en sistemas agrícolas es un elemento constitutivo de los modos de vida de las comunidades tradicionales de Brasil. Sin embargo, los organismos ambientales suelen considerarla una técnica a ser superada e imponen formas de manejo basadas en la biología de la conservación y en un régimen de conocimiento tecnocientífico. El estudio de caso presenta parte de los resultados de una investigación sobre los conflictos entre comunidades tradicionales de la Serra da Canastra en el estado de Minas Gerais y una unidad de conservación sobrepuesta en sus territorios. 
Los ecosistemas locales, predominantemente de sabana, fueron manejados por las comunidades a lo largo de los últimos tres siglos. En la dinámica del paisaje, el fuego es un factor clave en la renovación de los pastizales.

En 1972 fue creado el Parque Nacional Serra da Canastra con el objetivo principal de proteger la naciente del río São Francisco, así como conservar ecosistemas singulares y especies endémicas del bioma Cerrado de Brasil, otro hotspot de la biodiversidad a nivel mundial.

La creación del parque en una región que se caracterizó históricamente por las actividades agropecuarias y mineras representó un cambio significativo en la dinámica de construcción del paisaje, pues restringió prácticas tradicionales como el manejo del fuego bajo el sistema de "tierras altas y tierras bajas"3. La prohibición del uso de las "tierras altas" a partir de la década de 1970 implicó la restricción del manejo de pastizales naturales e intensificó la utilización de gramíneas exóticas en las "tierras bajas" como una alternativa para la alimentación del ganado (ver Imagen 3). Además, se experimentó una substitución gradual del ganado mestizo -como el pé-duro y el caracu- por razas genéticamente mejoradas, lo que contribuyó también a la restricción del manejo de pastizales.
Las familias de la región perciben un aumento en la frecuencia y la intensidad de las quemas como resultado de la prohibición del manejo tradicional del fuego, tanto en las "tierras altas" como en las "bajas". Según los habitantes, lo que ocurre hoy son "incendios", diferentes de las quemas controladas que se realizaban comunitariamente en el pasado. La prohibición del uso tradicional del fuego provoca una gran acumulación de macega (materia orgánica muerta), que funciona como combustible, lo que vuelve casi imposible controlar una quema, sea natural, producto de la acción de rayos, o intencional.

A pesar de que en los últimos años han existido esfuerzos del Instituto Chico Mendes (ICMBio) (encargado de la gestión de las unidades de conservación en Brasil) y otros organismos ambientales por comprender el papel del fuego en las dinámicas ecosistémicas y culturales, su prohibición ha generado más daños que beneficios para la unidad de conservación. De la misma manera, al negar los derechos de las comunidades tradicionales a utilizarlo ha proliferado el uso de quemas "criminales" como una acción de protesta, lo que ha colocado al fuego como un elemento central en los conflictos socioambientales experimentados en la región.

Imagen 3. Ganado alimentándose en las zonas en disputa y panorámica donde se aprecia la diferencia entre "tierras altas" y "tierras bajas". Imágenes de 2017.
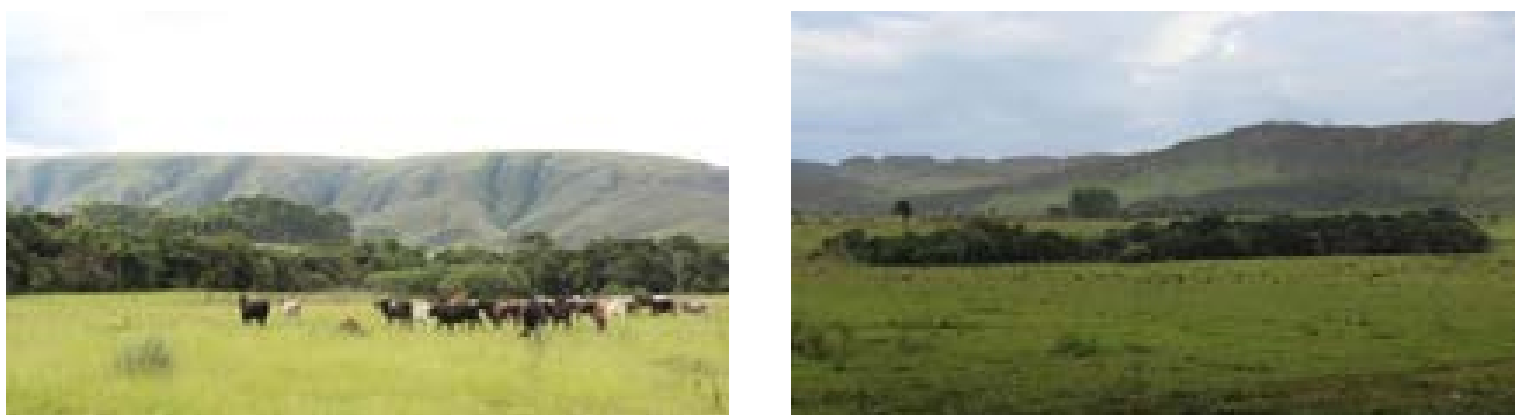

Fotografías: Acervo Projeto Mapeamento de Povos e Comunidades Tradicionais. 
Conservación de lugares de vida en la Patagonia chilena: el caso del Área Marina Protegida Pitipalena-Añihué

El sur austral de Chile es una región sujeta a múltiples intereses económicos y presiones ambientales, donde conviven la industria trasnacional acuícola, como la salmonicultura y mitilicultura, con comunidades indígenas, pescadores artesanales y campesinos que dependen, para su subsistencia, de la explotación directa de los recursos naturales (Álvarez y Navarro, 2010; Skewes, Álvarez \& Navarro, 2012). Amparado en un régimen privatizador de la zona costera, la industria acuícola se ha extendido en todo el sur austral de Chile, transformándose en la principal actividad económica de esta zona del país (Tecklin, 2016). Producto de la intensidad productiva y de una legislación laxa, los impactos ambientales se han multiplicado detonando crisis sanitarias de gran envergadura, que han comprometido la integridad de los ecosistemas y los modos de vida de las comunidades asentadas en los canales, fiordos e islas patagónicas (Román, Barton, Bustos \& Salazar, 2015; Bustos-Gallardo, 2017).

En este contexo se crea en 2014 el Área Marina Protegida (AMP) Pitipalena-Añihue, en la zona adyacente al poblado de Puerto Raúl Marín Balmaceda, localizado en el fiordo Pitapalena, en la Patagonia Norte. Aprovechando el interés de la comunidad científica y de organizaciones conservacionistas nacionales e internacionales por la protección de grandes cetáceos en el golfo de Corcovado ${ }^{4}$, emerge y se consolida una red de múltiples agentes que ven en la creación de una unidad de conservación un modo plausible de detener la expansión de la acuicultura industrial en el entorno del poblado. Para los habitantes de Raúl Marín Balmaceda, la imagen de Chiloé plagada de centros de cultivo de salmón, la suciedad de las playas productos de los desechos de las actividades productivas y la reducción de los recursos naturales aparecen como una imagen prototípica de un futuro no deseado, mientras que el fiordo, el río, la playa, los delfines, surgen como antítesis de un maritorio devastado.

El AMP, por lo tanto, surge como una herramienta de control del territorio de base local capaz de reorientar, frente a la amenaza de la expansión de la acuicultura, el uso de los bienes y los espacios comunes de la localidad hacia actividades de bajo impacto ambiental (Araos, 2018). De esta manera, se observa que más allá del objeto de protección declarado del AMP asociado a especies o hábitats específicos, el área busca proteger el lugar de vida de la comunidad de Raúl Marín Balmaceda. Es decir, el lugar común en el que los diversos seres que habitan este espacio socioecológico se encuentran, relacionan y desarrollan.

Frente a una política pública de privatización de los espacios y recursos comunes de la zona marino-costera de Chile destinada a promover la industria acuícola, observamos, en este caso, un ejercicio local emergente de gestión y control del maritorio y los bienes comunes que utiliza estratégicamente los espacios que los sistemas normativos dejan abiertos con el objetivo de impulsar transformaciones en el modo de usar y habitar este territorio (Araos y Ther, 2017). 
Imagen 4. Islas Hermanas y fiordo Pitipalena, sectores protegidos por el AMP Pitipalena-Añihue. Imágenes de enero de 2017.
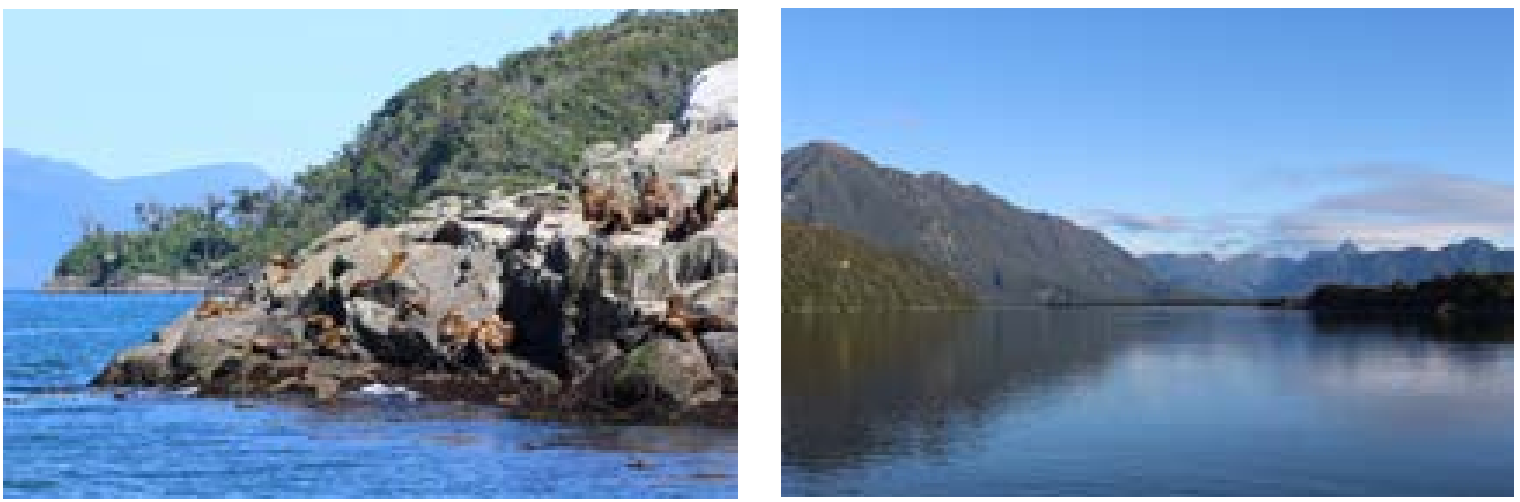

Fotografías: Francisco Araos.

Ciencia abierta en el litoral del sudeste brasileño: diálogo de saberes para el bien común

Los municipios costeros de Ubatuba (estado de São Paulo) y Paraty (estado de Río de Janeiro) se localizan en el bioma Mata Atlántica, una región brasileña que alberga una gran variedad de ecosistemas de importancia mundial (Dias-Brito, Milanelli, Riedel \& Wieczorek, 2014), que desempeñan un papel esencial para los modos de vida de las comunidades que habitan esta zona (Barbier, Hacker, Kennedy, Koch, Stier \& Silliman, 2011).

Por su importancia biológica, la región cuenta con un gran número de áreas protegidas (Parque Estatal Serra do Mar, Parque Nacional da Bocaina, Área de Protección Ambiental Marina del Litoral Norte de São Paulo, entre otros) que se han establecido bajo una política de "arriba hacia abajo" altamente excluyente que ha omitido e invisibilizado los factores sociales, culturales y políticos de los territorios (Simões, 2015; Iwama y Delgado, 2018). Así, es frecuente encontrarse con normas y reglas que prohíben el uso de los recursos naturales por parte de las comunida- des, asociadas, en su mayoría, a la agricultura de subsistencia y la caza de algunas especies, tradicionalmente usadas por las comunidades (Adams, 2000; Simões, 2015).

Bajo este marco de imposición de sistemas normativos propios de políticas excluyentes y restrictivas de conservación de la biodiversidad y gestión de los recursos naturales, se han registrado algunas experiencias de acción colectiva que han incentivado la reapropiación de los bienes y los espacios comunes a nivel local y regional.

Se destaca, en este sentido, el proyecto Ciencia Abierta Ubatuba ${ }^{5}$, desarrollado entre 2015 y 2017, en coordinación con el Instituto Brasileño de Información en Ciencia y Tecnología (IBICT), con el objeto de promover la articulación entre investigación científica, comunidades y organizaciones de la sociedad civil. El proyecto abrió el campo para la realización de prácticas científicas abiertas y colaborativas, en especial para la creación de puentes entre ciencia y desarrollo local (Albagli, Parra, Fonseca \& Maciel, en prensa; Fonseca, Albagli, Parra \& Maciel, 2016). 
El foco de estas prácticas lo constituyeron temas como los datos geoespaciales ${ }^{6}$ y la ciencia ciudadana para la adaptación a los cambios climáti$\cos ^{7}$, a partir de los cuales se formaron núcleos de aprendizaje en el territorio.

Asimismo, fue creada una plataforma participativa de geovisualización de datos abiertos en el territorio, llamada LindaGeo (Litoral Norte Datos Abiertos Geoespaciales) (Iwama, Silva, Ballabio \& Fonseca, 2017). En su desarrollo se buscó movilizar, involucrar e intercambiar experiencias, demandas y expectativas entre diferentes grupos locales, tales como el Comité de Cuencas Hidrográficas del Litoral Norte, el Área de Protección Ambiental Marina (APAMLN), escuelas públicas, investigadores de universidades, además de miembros del Foro de Comunidades Tradicionales $\left(\mathrm{FCT}^{8}\right)$, a través del Observatorio de Territorios Sostenibles y Saludables de la Bocaina $\left(\right.$ OTSS $^{\circ}$ ). En 2018, el grupo logró reunir doce instituciones de diferentes sectores y cerca de sesenta miembros interesados en desarrollar dicha plataforma como una acción estructurada de largo plazo.

La experiencia LindaGeo se apoya en una perspectiva de ciencia abierta y colaborativa (Albagli, Clinio, Parra \& Fonseca, 2018; Albagli, Maciel \& Abdo, 2015; Santos, Almeida \& Henning, 2017; Mirowski, 2018), que representa una forma de conocer que apela a lo común, para el bien común. El diálogo de saberes y la incorporación de valores se constituye en ella como base para la generación de confianzas entre formas de habitar, conocer el territorio y producir el conocimiento entre los diversos actores y grupos sociales, como los caiçaras, los indígenas y las quilombolas (las comunidades tradicionales) ${ }^{10}$. Se trata, por lo tanto, de experiencias de construcción de conocimientos de "abajo hacia arriba", en cuyo proceso de conformación se van incorporando nuevos actores. Con ello se amplían los niveles y las dimensiones de la acción colectiva para la construcción de un aprendizaje en comunidad (Freire, 1967; Rodrigues de Mello, Marini \& Gabassa, 2012; Pacheco, 2014).

Imagen 5. (a) Mapa de la Zonificación Ecológico-Económica del litoral norte y plan director de Ubatuba - visualizando superposiciones de zonas; (b) Taller del SIG ${ }^{11}$ (QGIS) para la comunidad en el LabUbaGeo; (c) Pueblo de pescadores de Picinguaba. Imágenes de 2016-2018.

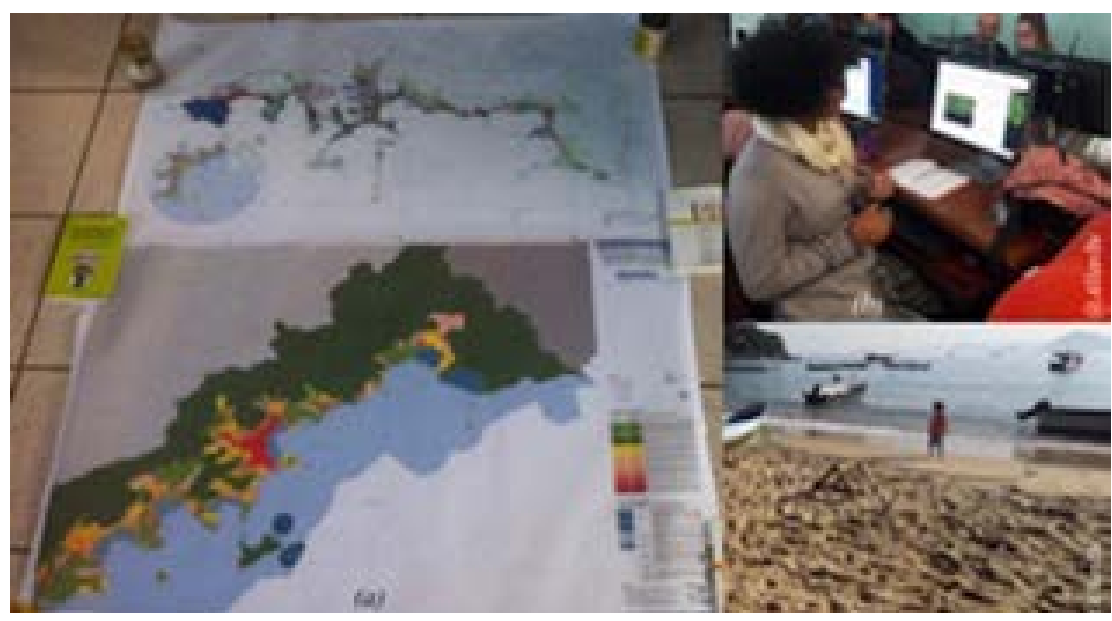

Fotografías adaptadas: Allan Iwama. 


\section{La vida después de la devastación}

En este apartado discutiremos los tres ejes identificados anteriormente. Cada uno de ellos se asocia a alguna dimensión específica de los estudios de caso. Consideramos las investigaciones sobre el fuego en Pumanque y en la Serra da Canastra como experiencias significativas para comprender la idea de siniestro normativo, mientras que las investigaciones sobre conservación en la Patagonia norte y el diálogo de saberes en el litoral del sudeste brasileño se presentan como experiencias clave para entender la relación entre micropolíticas y procesos emergentes. Estos dos primeros ejes funcionan como polos de atracción en la trayectoria de desarrollo de los bienes y espacios comunes al orientar su desenvolvimiento hacia el colapso de los sistemas o bien hacia su recomposición a partir del surgimiento de nuevos atractores. La regeneración de la vida, a su vez, emerge como una salida o transición en esta trayectoria de desarrollo, como una posibilidad de ir más allá de las reincidencias y similitudes de la tragedia y ofrecer, al menos analíticamente, una vía para reinventar lo común de la vida.

\section{Siniestros normativos}

La idea de siniestro normativo surge tras analizar las experiencias asociadas al uso del fuego entre las comunidades campesinas de los casos de Brasil y Chile, y refiere a cambios profundos en los sistemas normativos tradicionales que organizaban el modo de usar y habitar los bienes y los espacios comunes. Observamos que los siniestros normativos anteceden a la tragedia de los comunes como detonantes de transformaciones radicales en los sistemas locales de manejo y apropiación de los recur- sos naturales, que colocan a los sujetos y sus prácticas bajo la condición de "ilegales" o poco eficientes. Tanto la política violenta e impositiva de creación de unidades de conservación en Brasil, ejemplificada en el caso del Parque Nacional Serra da Canastra, como las leyes de fomento forestal en Chile en el caso de Pumanque, nos muestran los efectos perversos de la imposición de la razón gubernamental sobre los regímenes de conocimientos tradicionales, con consecuencias no solo para las propias comunidades que perciben negados y violentados sus derechos sobre el territorio, sino también para la misma biodiversidad.

De esta forma, vemos que la tragedia ya no está dada ni por la inexistencia de un Leviatán externo que regule los intereses individuales tal y como lo propuso Garret Hardin, ni tampoco por la inoperancia de alguno de los principios para el buen gobierno de los comunes propuestos por Elinor Ostrom. Más bien se da por el despliegue de una racionalidad monolítica -expresada en el Estado y los actores económicos-que define los modos legítimos de usar y habitar los bienes y los espacios comunes. Nada más y nada menos que un verdadero homo homini lupus cultural del siglo XXI. Frente a esta situación, las poblaciones tienen escasas capacidades para reaccionar con la vitalidad que poseían antaño, pues muchas de las estrategias están deslegitimadas o incluso colocadas al margen de la legalidad, lo que provoca la pérdida de conocimientos y prácticas consuetudinarias que les habían permitido sortear múltiples crisis ambientales previas.

Asimismo, el siniestro normativo es la expresión empírica de una fractura más profunda producida por el despliegue del capitalismo avanzado sobre territorios sociobiodiversos. Esta tiene que 
ver con el conflicto ontológico que se establece entre los diversos mundos que se encuentran y desencuentran en estos espacios de vida (Blaser, 2013). Visto de esta manera, el conflicto ya no es solo el resultado de diferencias entre las formas de conocer y apropiarse la naturaleza de los grupos locales (saber tradicional) y de los actores económicos y/o gestores estatales (saber tecnocientífico), sino que es consecuencia de la contradicción radical entre ontologías que definen la constitución de los seres y la vida en el planeta, ya sea como un ensamblaje de entidades humanas y no humanas en constante comunicación e interacción, o bien como una separación clara entre el dominio del hombre y el de la naturaleza (Escobar, 2008; Blaser, 2009; De la Cadena, 2010; Povinelli, 2014; Kohn, 2015). Así, ya no basta con establecer mecanismos de diálogo temprano, responsabilidad social o mitigación de impactos para gestionar los conflictos, más bien se requieren estrategias para recomponer los canales de comunicación entre los seres que incentiven la resurgencia de la vida y que puedan traducirse en arreglos socioambientales capaces de resguardar estos procesos vitales.

\section{Micropolíticas emergentes}

La emergencia de nuevos arreglos socioambientales en el marco de la implementación de políticas de conservación y gestión de los territorios da cuenta, precisamente, de ejercicios de reapropiación de bienes y espacios comunes esenciales para la mantención de los procesos vitales de los sistemas socioecológicos locales. Esta situación es particularmente visible en los casos asociados a territorios marino-costeros presentados en este artículo, donde la acción colectiva de redes y coaliciones de agentes y organizaciones sociales ha permitido impulsar iniciativas para la protección de los lugares y los modos de vida de las comunidades, ya sea utilizando los mecanismos institucionales que dispone el Estado, como es el caso de la AMP Pitipalena-Añihue, o bien recomponiendo los canales de diálogo entre los habitantes de la zona costera de Ubatuba y Paraty para la reconfiguración de los territorios tradicionales del sudeste de Brasil.

Estos arreglos son la expresión de ejercicios micropolíticos desplegados al interior de tensiones territoriales producidas por el avance y la consolidación de las industrias extractivistas y neoextractivistas -acuicultura, turismo de masas, petróleo y gas, forestal, entre otrassobre los espacios y bienes comunes. Surgen del impulso creativo de un amplio conjunto de agentes para apropiarse o reconfigurar los sistemas normativos que orientan el modo de usar y habitar estos territorios. Estas organizaciones asumen la forma de ensamblajes ecopolíticos en cuanto congregan agentes, instituciones, discursos y entidades no humanas -como la biodiversidad-con el objetivo de transformar los sistemas normativos que afectan los bienes comunes a escala local y regional (Araos, 2017, 2018). La emergencia está dada, así, por la composición de elementos heterogéneos y su transformación en una entidad independiente de sus componentes originales que, una vez territorializada, tiene el potencial para influenciar en el conjunto de entidades que se disponen en otros niveles de la escala espacial o normativa (Collier \& Ong, 2005; Delanda, 2006; Anderson, Kearnes, McFarlane \& Swanton, 2012).

Esto último queda de manifiesto, efectivamente, en la asociación de las áreas marinas protegidas con los lugares de vida/territorios tradicionales de las comunidades locales, cuya orientación hacia 
la apropiación colectiva sobre los bienes comunes viene a contrarrestar el régimen privatizador de la zona costera materializado en la concesión de áreas para la acuicultura, el desarrollo inmobiliario y portuario. De la misma forma, estas iniciativas permiten ampliar el horizonte de la conservación de la biodiversidad al incluir la gestión local de las unidades de conservación e incorporar en los diseños institucionales figuras que van más allá de la acción del Estado y de conservacionistas privados (Araos y Ther, 2017).

En el caso de Ubatuba-Paraty, por ejemplo, las innovaciones colocan en evidencia la inexistencia de una dicotomía entre los comunes "naturales o materiales" y los comunes "del conocimiento", pues estos se implican mutuamente, en una dinámica ecopolítica, donde el derecho a la vida en el territorio es una condición para la existencia de una ecología de saberes que integra lo común de la socio y la biodiversidad (Albagli et al., 2018).

Se trata, por lo tanto, de estrategias que buscan "escalar" las innovaciones locales sobre la base de la participación e integración de lo común: (a) hacia arriba (en el ordenamiento institucional), (b) hacia afuera (hacia otros sectores de la sociedad), (c) hacia adentro (en las normas y los valores culturales) (Moore, Riddell \& Vocisano, 2015), e incentivar, con esto, transiciones en los modos de habitar los territorios (Patterson et al., 2017). En un sentido amplio, se trata de soluciones creativas, nacidas de la intersección entre actores, estrategias, socio y biodiversidad.

\section{Regeneración de la vida}

Los casos de Chile y Brasil sobre el fuego son campos fructíferos para comprender el modo en que opera la regeneración de la vida en los sistemas socioecológicos locales, expresada en el aprendizaje territorial de las comunidades locales acerca de los comportamientos, las intenciones y los performances de los seres no humanos que se entrelazan en el devenir de la quema y el incendio tanto en las prácticas tradicionales de manejo de pastizales de la Canastra como en el arreo del fuego en la catástrofe de la zona central de Chile. El fuego, en estos lugares, devino en incendio cuando transformó su composición inicial de quema manejada por el saber local en llamarada salvaje propagada por los monocultivos industriales de Pumanque o por las florestas protegidas del Parque Nacional Serra da Canastra.

El fuego aprovechó el combustible orgánico e inorgánico dejado por el despliegue de la razón neoliberal sobre los bienes y los espacios comunes para propagarse y transformarse en incendio. Desde este punto de vista, la catástrofe no se ancla en la pérdida o la reducción de los bienes comunes, la biodiversidad, los servicios ecosistémicos o los recursos naturales provocadas por las industrias neoextractivistas y la razón gubernamental, sino que por la clausura de las conexiones y las vías de comunicación que tejen el mundo relacional entre humanos y no humanos (Kohn, 2007). Entra en cuenta el aislamiento ontológico de los seres producido por la imposición de regímenes de ser y conocer en los que la discontinuidad de los procesos vitales se yergue como principio organizador de la vida.

De esta manera, fue la capacidad de conocer, comunicarse y entender el comportamiento del fuego lo que permitió a los habitantes de Pumanque "controlar la bestia", arreando el incendio lejos de las zonas habitadas. No se 
requirieron de las grandilocuencias de los aviones cisternas Supertanker e Ilyshin ${ }^{12}$ para aplacar la tormenta, bastó con apelar a la pertinencia del vínculo histórico que ha sostenido la vida en esta zona de la región central de Chile, que es la que otorga sustento a lo común en áreas rurales (Williams, 2001).

La regeneración de la vida está dada, en este contexto, por la adecuación mutua y recíproca de las múltiples entidades que conforman el mundo, cuya comunicación e interacción deviene en nuevos paisajes socionaturales, donde el buen vivir de unos -humanos-depende del buen vivir de otros -más que humanos(De la Cadena, 2015). La deriva política de la regeneración de la vida transita, de esta forma, hacia la constitución y la defensa del pluriverso (De la Cadena, 2010; Escobar, 2012) como una nueva utopía basada en:
[...] la redefinición de las bases de lo político, desde aquello donde lo político comienza con una definición hegemónica que sostiene la superioridad de la concepción y de las prácticas socionaturales de Occidente, hacia otra que comienza con el entendimiento simétrico sobre mundos diversos, sus concepciones y prácticas socionaturales (De la Cadena, 2010, p. 361).

Mirado de esta manera, la resolución de conflictos socioambientales como los presentados en este texto no se restringe a la devolución, la protección y/o la regularización de los bienes y los espacios comunes -algo extremadamente necesario, pero insuficiente en apariencia-, sino que requiere de una reelaboración simétrica de la relación política entre mundos diversos (Blaser, 2009) que incentive la regeneración de la vida después de la devastación (Tsing, 2015).

Imagen 6. Árbol quemado producto de los incendios en Pumanque en proceso de regeneración.

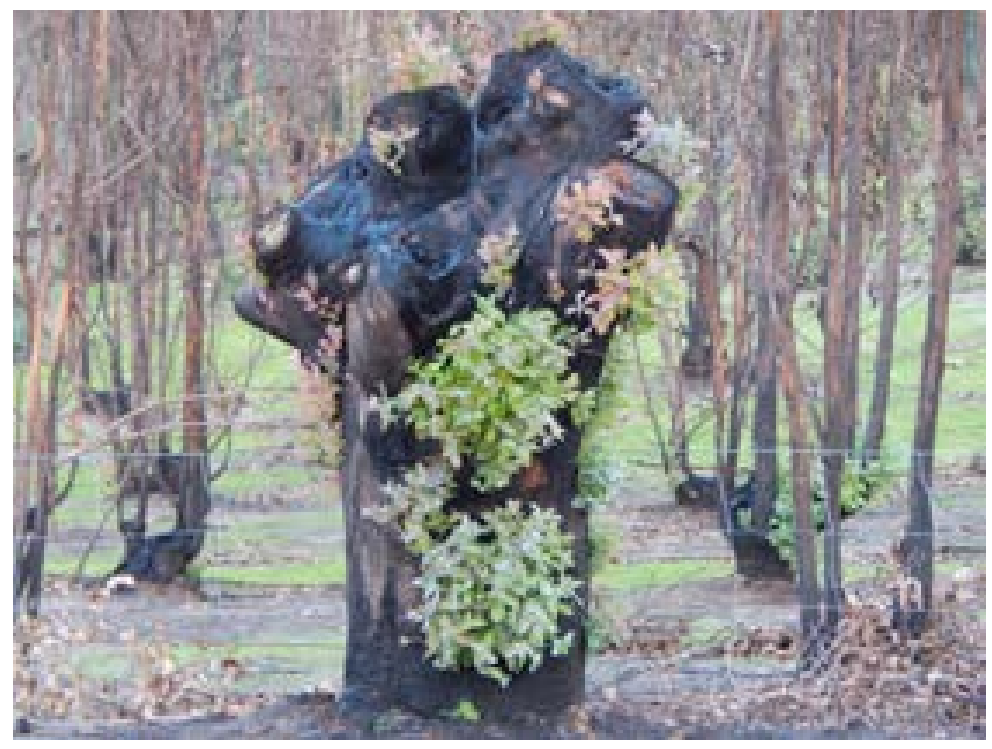

Fotografía: Wladimir Riquelme. 


\section{Conclusiones}

Entre un poblado costero asediado por la industria del salmón y un incendio descomunal fruto de plantaciones forestales inspiradas por la maximización económica, constatamos la existencia de modos locales de articular las prácticas culturales con el medio ambiente que han sido literalmente arrasadas por el fuego o por la expansión inmobiliaria. En ello radica la catástrofe, a saber, en el desalojo de poblaciones cuya experiencia de vida proveía de protecciones de las que ahora el paisaje carece. Esto es lo común de la tragedia en Chile, en Brasil $y$, nos arriesgamos a decir, en otras partes del planeta: la degradación de los procesos vitales que sostienen la existencia y el devenir de los sistemas socioecológicos.

Los casos de Pumanque, el Parque Nacional Serra da Canastra, el Área Marina Protegida Pitipalena-Añihué y Ubatuba-Paraty son, precisamente, ejemplos para entender cómo opera la devastación y la regeneración de la vida en sus diferentes fases $y$ tiempos. Es decir, ya sea bajo la imposición violenta de regímenes de propiedad y conocimientos sobre los sistemas locales de uso de bienes y espacios comunes, o bien como ejercicios micropolíticos de reapropiación e innovación local de arreglos socioambientales con el potencial para transformar los modos de habitar los territorios comunes. Devastación y regeneración como dos caras del devenir de la vida.

Los casos aquí discutidos invitan, en su conjunto, a una reflexión crítica acerca de la relación entre la agencia pública, la acción colectiva y la ciencia. A partir de ellos se pueden identificar no solo los nudos críticos de esta relación, sino que también las oportu- nidades que se generan en el encuentro de estos distintos sistemas normativos y su implementación. El arreo del fuego descrito por los residentes de Pumanque como un medio de combatir los incendios forestales constituye una valiosa metáfora para dar cuenta de los acoples y los desacoples entre las prácticas locales y la gestión pública. Los sistemas normativos impuestos "desde arriba" importan desórdenes en el "abajo". Es el caso de la definición de las prácticas de cultivo basadas en la roza y la quema y que tanto la autoridad pública como la ciencia ambiental consideran como obsoleta. Sin embargo, la experiencia de las comunidades tradicionales de la Serra da Canastra en el estado de Minas Gerais ha demostrado, en trescientos años, que tales prácticas han sido capaces de conservar el paisaje de mejor modo que los planes de manejo inspirados por la racionalidad científica.

Los desajustes, no obstante, invitan a reposicionamientos emergentes que amplían los márgenes de la conversación entre cientistas, planificadores y actores locales. Los habitantes de Raúl Marín Balmaceda han encontrado, en el contexto del Área Marina Protegida Pitipalena-Añihué, espacios nuevos para el despliegue de sus propios proyectos, misma oportunidad que se advierte en el sudeste brasileño. Ello da como resultado no solo la reapropiación de los recursos que, por la imposición normativa, les habían sido enajenados, sino que también abre la posibilidad de generar nuevas formas de diálogo que integren las visiones de la ciencia y de los propios actores. La plataforma participativa de geovisualización del Litoral Norte Datos Abiertos Geoespaciales es un ejemplo de ello.

De lo anterior se desprende que, en un contexto de discordancia entre los sistemas 
normativos formales y las prácticas locales tanto en Brasil como en Chile, existen lecturas alternativas que permiten aprovechar tales contradicciones para ponerlas al servicio, por una parte, de las propias comunidades, y, por la otra, de los objetivos de la conservación. El "arreo del fuego", en este caso, expresa el acomodo recíproco entre ciencia, planificación y comunidad, en el que la conservación ha de entenderse, de manera simultánea, como un proceso socialmente inclusivo.

Las experiencias sugieren que, aun cuando la catástrofe ha ocurrido, la regeneración de la vida cobra nuevos bríos cuando se ancla en la trayectoria vital de los grupos locales. La imagen del árbol quemado en cuyo tronco comienzan a multiplicarse los brotes verdes ilustra la trayectoria de este territorio y el poder vital que se despliega localmente (Mathews, 2017). Al detenernos en la fotografía vemos que alrededor de la imagen central del árbol talado y quemado hay un conjunto de elementos que conforman el "paisaje embrujado" (haunted landscapes) (Gan, Tsing, Swanson \& Bubandt, 2017) de Pumanque, tal ánimas de vidas pasadas que reaparecen en el presente: el árbol talado, quemado, el suelo agotado y erosionado, las hojas secas que cubren la tierra, los alambrados que separan los predios, los renovales de eucaliptus perfectamente alineados en el horizonte. Una composición que revela el impacto de la expansión de la industria forestal en los paisajes rurales de la zona central de Chile en los últimos cincuenta años y que muestra cómo el espacio común ha sido dividido y fragmentado por la propiedad privada y que pone en evidencia la hegemonía de una racionalidad que restringe y poda el crecimiento de las plantas. Pero este paisaje embrujado, no obstante, resurge desde los "restos" del árbol quemado, de la cepa y del tronco, en cuya corteza reverberan los luminosos verdes que aclaran el opaco sepia de las plantaciones incendiadas. Después de la devastación, después de la desorganización generada por la crisis, con la reorganización se regenera la vida. Todo un paisaje de clivajes que por algún ángulo o intersticio se abre y redescubre a sí mismo en consideración de la densificación del tiempo en la semilla, que no es otra cosa que vida en proyección.

El antropoceno es el trasfondo de las múltiples prácticas de vida que analizamos en este artículo, algunas cuya virtud radica en la posibilidad de, tras el desastre, "vivir en un mundo dañado", tal como lo sugieren Tsing, Swanson, Gan \& Bubandt (2017). Tratamos, en este sentido, de "anticipar algo de lo que ya somos parte" (Morton, 2018, p. 23). La experiencia de la devastación y de la regeneración, de la muerte y de la vida, ya es conocida: el futuro incierto del antropoceno y la crisis ambiental global ya están siendo vividos y hay quienes ya han experimentado -como las comunidades locales aquí lo sugieren-con las posibles respuestas.

Así emerge y se reinventa lo común, puesto ahora al servicio del bien común. Queda, pues, en manos de las comunidades locales reverdecer las tierras que sostienen sus vidas: si el arreo enseñó a domeñar el fuego, será el arreo lo que promueva el repoblamiento de los campos. Entre los fantasmas de la devastación que surgen en el contexto del antropoceno cabe, pues, dar con los enjambres de la vida, con los enredos, las imbricaciones, las mixturas o entaglements que sugieren los tipos de paisajes que pueden hospedar otras formas de vivir con/en/después de la devastación. 
De aquí, finalmente, se desprende la necesidad de imaginar el antropoceno como el "fin del mundo moderno" -el mundo de los humanos-, para navegar, esta vez, no hacia un "nuevo mundo", sino que a una renovación ontológica de la vida en el planeta (Danowski y Viveiros de Castro, 2014). Es necesario abrirse a la posibilidad de su regeneración sobre la base de otras/nuevas composiciones entre humanos y no humanos. Es ahí, justamente, donde las y los antropólogos/as pueden ayudar en el diseño de nuevos sueños, en el codiseño de la vida en el planeta.

\section{Notas}

${ }^{1}$ El artículo reúne los trabajos y las reflexiones presentadas en el panel "Territorial Management: Experiences from Brazil and Chile", realizado en julio de 2018 en el Congreso de la International Union of Anthropological and Ethnological Sciences (IUAES), en la Universidad Federal de Santa Catarina, Brasil.

${ }^{2}$ Nombre puesto por la CONAF (Corporación Nacional Forestal) para describir y analizar los efectos del incendio de 2017. Descripción y efectos "Tormenta de Fuego", 2017. Recuperado el 10 septiembre 2017 de http://www.conaf.cl/tormenta_de_fuego-2017/ DESCRIPCION-Y-EFECTOS-TORMENTA-DE-FUEGO-18-ENEROAL-5-FEBRERO-2017.pdf

${ }^{3}$ Las tierras altas, denominadas localmente como chapadas o chapadões, eran utilizadas por los campesinos como área de pastoreo para el ganado durante el período de sequía, entre agosto y noviembre. Algunos pobladores construían retiros-construcciones rústicas, de piedra, con pocas comodidades- que eran habitados durante el pastoreo. En la época de lluvias se practicaba el manejo del fuego en los valles, denominado "fogo brando", con la intención de incentivar el rebrote de gramíneas nativas destinadas a la alimentación de los animales.

${ }^{4}$ Recuperado de http://wwf.panda.org/es/?216991/Con-nuevoParque-Marino-Tic-Toc-Chile-da-un-paso-decisivo-en-la-conservacin-de-su-mar-y-de-especies-emblemticas-como-la-ballena-azul\#.

\section{Referencias bibliográficas}

Abaleron, C. (2010). De la Tragedia de los Comunes a lo común de las tragedias. Lider, 12(17), 37-52.

Adams, C. (2000). As populações caiçaras e o mito do bom selvagem: a necessidade de uma nova abordagem interdisciplinar. Revista de Antropologia, 43(1), 145-182.

Albagli, S., Maciel, M. L. \& Abdo, A. (2015). Open Science, Open Issues. Brasília, Río de Janeiro: Instituto Brasileiro de Informação en Ciência e Tecnologia, Universidad Federal del Estado de Río de Janeiro.

Albagli, S., Clinio, A., Parra, H. \& Fonseca, F. (2018). Beyond the Dichotomy between Natural and Knowledge Commons: Reflections

\footnotetext{
${ }^{5}$ Ciência Abierta Ubatuba. Recuperado el 30 abril 2018 de http:// wiki.ubatuba.cc/doku.php?id=cienciaaberta:cienciaaberta

${ }^{6}$ LindaGeo. Litoral Norte Dados Abertos Geoespaciais. Recuperado el 30 abril 2018 de http://wiki.ubatuba.cc/doku.php?id=linda:lindageo

${ }^{7}$ CoAdapta/Litoral. Recuperado el 30 abril 2018 de http://wiki. ubatuba.cc/doku.php?id=coadapta_litoral:coadapta

${ }^{8}$ Foro de Comunidades Tradicionales (FCT). Recuperado de http://www.preservareresistir.org/

${ }^{9}$ Observatório de Territórios Sustentáveis e Saudáveis da Bocaina (OTSS). Recuperado el 30 abril 2018 de http://otss.org.br/

${ }^{10}$ Caiçaras: poblaciones asentadas en la zona costera de Brasil, en especial en el sur y sudeste del país, dedicadas a la pesca artesanal y la agricultura de subsistencia. Quilombolas: poblaciones afrodescendientes con antepasados negros vinculados a la resistencia a la opresión esclavista.

${ }^{11}$ Ver http://wiki.ubatuba.cc/doku.php?id=linda:2018_minioficina_lindageo

${ }^{12}$ Aviones cisternas de gran capacidad de origen estadounidense y ruso, respectivamente, utilizados para el combate a los incendios. Para más información ver: http://www.emol.com/noticias/ Nacional/2017/01/26/842052/Como-se-comparan-las-caracteristicas-del-Supertanker-y-el-avion-ruso-que-se-suma-al-combate-delas-llamas.html
}

on the IAD Framework from the Ubatuba. Open Science Project. En Chan, L. \& Mounier, P., 22nd International Conference on Electronic Publishing. Toronto: University of Toronto.

Albagli, S., Parra, H., Fonseca, F. \& Maciel, M. L. (en prensa). Open Science and Community Development: An Action-research in Ubatuba, Brazil. En Chan, L. (Ed.), Contextualizing and Situating Openness: Understanding the Diversity and Contexts of Open Science in Development. Ottawa: University of Ottawa Press.

Álvarez, R. \& Navarro, M. (2010). Conflictos asociados a los múltiples usos. En Hucke-Gaete, R., Lo Moro, P. \& Ruiz, J. (Eds.), Conservando el mar de Chiloé, Palena y las Guaitecas. Síntesis 
del estudio investigación para el desarrollo de Área Marina Costera Protegida Chiloé, Palena y Guaitecas (pp. 125-143). Puerto Montt: Gobierno Regional de Los Lagos.

Anderson, B., Kearnes, M., McFarlane, C. \& Swanton, D. (2012). On Assemblages and Geography. Dialogues in Human Geography, 2(2), 171-189.

Araos, F. (2017). Más allá de la biodiversidad: aportes de la antropología a la conservación marina en Chile. Revista Austral de Ciencias Sociales, (33), 21-35.

(2018). Navegando en aguas abiertas: tensiones y agentes en la conservación marina en el sur austral de Chile. Revista de Estudios Sociales, (64), 27-41. doi: https://doi.org/10.7440/ res64.2018.03

Araos, F. \& Ther, F. (2017). How to Adopt an Inclusive Development Perspective for Marine Conservation: Preliminary Insights from Chile. Currunt Opinion in Environmental Sustainability, (24), 68-72. doi: https://dx.doi.org/10.1016/j.cosust.2017.02.008.

Arroyo, M., Marquet, P., Marticorena, C., Simonetti, J., Cavieres, L., Squeo, F., Rozzi, R. \& Massardo, F. (2008). El hotspot chileno, prioridad mundial para la conservación. En Rovira, J., Ugalde, J. \& Stutzin, M. (Eds.), Biodiversidad de Chile. Patrimonio y desafíos (pp. 90-115). Santiago: Comisión Nacional del Medio Ambiente, Ocho Libros.

Barbier, E., Hacker, S., Kennedy, C., Koch, E., Stier, A. \& Silliman, B. (2011). The Value of Estuarine and Coastal Ecosystem Services. Ecological Monographs, 81(2), 169-193.

Basso, K. (1996). Wisdom Sits in Places: Landscape and Language among the Western Apache. Albuquerque: University of New Mexico Press.

Blaser, M. (2009). The Threat of the Yrmo: The Political Ontology of a Sustainable Hunting Program. American Anthropologist, 111(1), 10-20. doi: http://dx.doi.org/10.1111/j.1548-1433.2009.01073.

(2013). Ontological Conflicts and the Stories of People in Spite of Europe. Current Anthropology, 54(5), 547-568. doi: http:// dx.doi.Org/10.1086/672270

Bustos-Gallardo, B. (2017). The Post 2008 Chilean Salmon industry: An Example of an Enclave Economy. The Geographical Journal, (183), 152-163. doi: http://dx.doi.org/10.1111/geoj.12204

Cadena, M. de la (2010). Indigenous Cosmopolitics in the Andes. Conceptual Reflections beyond 'Politics'. Cultural Anthropology, 25(2), 334-370. doi: http://dx.doi.org/10.1111/j.1548-1360.2010.01061.x

(2015). Earth Beings. Ecologies of Practice across Andean Worlds. Durham, Londres: Duke University Press.

Collier, S. \& Ong, A. (2005). Global Assemblages: Technology, Politics, and Ethics as Anthropological Problems. Oxford: Blackwell.

Costanza, R. (2000). Social Goals and the Valuation of Ecosystem Services. Ecosystems, 3(1), 4-10. doi: https://doi.org/10.1007/ s100210000002

Costanza, R., D’Arge, R., De Groot, R., Farber, S., Grasso, M., Hannon, B., Limburg, K., Naeem, S., O'Neill, R., Paruelo, J., Raskin, R., Sutton, P. \& Van den Belt, M. (1997). The Value of the World's Ecosystem Services and Natural Capital. Nature, 387(6630),
253-260. doi: https://doi.org/10.1038/387253a0

Danowski, D. \& Viveiros de Castro, E. (2014). Há Mundo por Vir? Ensaio sobre os Medos e os Fins. Río de Janeiro: Instituto Socioambiental.

Delanda, M. (2006). A New Philosophy of Society. Assamblage Theory and Social Complexity. Nueva York: Continuum.

Descola, P. (2012). Más allá de la naturaleza y cultura. Buenos Aires: Amorrortu.

Descola, P. \& Pálsson, G. (2001). Naturaleza y sociedad: perspectivas antropológicas. México: Siglo XXI.

Dias-Brito, D., Milanelli, J., Riedel, P. \& Wieczorek, A. (2014). Sensibilidade do litoral paulista a derramamentos de petróleo: um atlas em escala de detalhe. Río Claro: Universidade Estadual Paulista.

Escobar, A. (2008). Territories of Difference. Place, Movements, Life, Redes. Durham: Duke University Press. (2012). Más allá del desarrollo: postdesarrollo y transiciones hacia el pluriverso. Revista de Antropología Social, (21), 23-62.

Feeny, D., Berkes, F., McCay, B. \& Acheson, J. (1990). The Tragedy of the Commons: Twenty-two Years Later. Human Ecology, 18(1), 1-19. doi: https://doi.org/10.1007/BF00889070

Fleming, P. (2017). The Death of Homo Economicus: Work, Debt and the Myth of Endless Accumulation. Londres: Pluto Press.

Fonseca, F., Albagli, S., Parra, H. \& Maciel, M. L. (2016). Ciência aberta e colaborativa no desenvolvimento: a experiência da Plataforma Ciência Aberta Ubatuba. XI Jornadas Latino-Americanas de Estudos Sociais da Ciência e da Tecnologia. Asociación Latinoamericana de Estudios Sociales de la Ciencia y la Tecnología, Curitiba.

Freire, P. (1967). Educação como prática da liberdade. Río de Janeiro: Paz e Terra.

Gan, E., Tsing, A., Swanson, H. \& Bubandt, N. (2017). Introduction: Haunted Landscapes of the Anthropocene. En Tsing, A., Swanson, H., Gan, E. \& Bubandt, N. (Eds.), The Arts of Living on a Damaged Planet: Ghosts and Monsters of the Anthropocene (pp. 145-156). Minneapolis: University of Minnesota Press.

Hardin, G. (1968). The Tragedy of the Commons. Science, 162(3859), 1243-1248. doi: https://doi.org/10.1126/science.162.3859.1243

Ingold, T. (2000). The Perception of the Environment: Essays on Livelyhood, Dwelling and Skill. Londres, Nueva York: Routledge. (2013). Making. Anthropology, Archaeology, Art and Architecture. Londres: Routledge.

Iwama, A. Y. \& Delgado, L. (2018). Acción: participación comunitaria en procesos de decisión en la conservación del territorio. Cuadernos del Pensamiento Crítico Latinoamericano, (56), 1-3. Recuperado de http://biblioteca.clacso.edu.ar/clacso/ se/20180516025156/CuadernoPLC-N56-SegEpoca.pdf

Iwama, A. Y., Silva, D. S., Ballabio, T. A. \& Fonseca, F. S. (2017). A Participação no Zoneamento Ecológico-Econômico no Litoral Norte de São Paulo: como estamos nesta discussão?. InforMar Ubatuba. Recuperado el 30 abril 2018 de http://informarubatuba.com.br/ participacao-no-zoneamento-ecologico-economico-no-litoral-nortede-sao-paulo-como-estamos-nesta-discussao/

Jack, B. (1989). The Question of the Commons: The Culture and 
Ecology of Communal Resources. Anthropology of Work Review, 10(2), 1-11. doi: https://doi.org/10.1525/awr.1989.10.2.1

Kohn, E. (2007). How Dogs Dream: Amazonian Natures and the Politics of Transspecies Engagement. American Ethnologist, 34(1), 3-24. doi: http://dx.doi.org/10.1525/ae.2007.34.1.3 (2013). How Forests Think: Toward an Anthropology Beyond the Human. Berkeley: University of California Press. (2015). Anthropology of Ontologies. Annual Review of Anthropology, (44), 311-327.

Latour, B. (1993). We Have Never Been Modern. Cambridge: Harvard University Press.

Mathews, A. (2017). Ghostly forms and forest histories. En: The Arts of Living on a Damage Planet. Editado por Anna Tsing, Swanson, H.A., Gan, E., Bubandt, N. pp. 145-156. Minneapolis: University of Minnesota Press.

Massey, D. (2005). For Space. Londres: Sage.

Mirowski, P. (2018). The Future(s) of Open Science. Social Studies of Science, 48(2), 171-203. doi: https://doi. org $/ 10.1177 / 0306312718772086$

Moraga, F. (2012). Pumanque. Los Cóndores. Santiago: Gamagraphic.

Morton, T. (2018). Being Ecological. Cambridge, Massachusetts: MIT Press.

Moore, M., Riddell, D. \& Vocisano, D. (2015). Scaling Out, Scaling Up, Scaling Deep: Strategies of Non-profits in Advancing Systemic Social Innovation. The Journal of Corporate Citizenship, (58), 67-84.

Ostrom, E. (1990). Governing the Commons: The Evolution of Institutions for Collective Action. Cambridge: Cambridge University Press.

(2007). Sustainable Social-ecological System: An Impossibility? En Annual Meetings of the American Association for the Advancement of Science. San Francisco: Well-Being.

Pacheco, J. (2014). Aprender em comunidade. São Paulo: SM.

Patterson, J., Schulz, K., Vervoort, J., Van der Hel, S., Widerberg, O., Adler, C., Hurlbert, M., Anderton, K., Sethi, M. \& Barau, A. (2017). Exploring the Governance and Politics of Transformations Towards Sustainability. Environmental Innovation and Societal Transitions, (24), 1-16. doi: https://doi.org/10.1016/j.eist.2016.09.001

Povinelli, E. (2014). "Geontologies of the Otherwise". Theorizing the Contemporary. Fieldsights, 13 enero. Recuperado de https:// culanth.org/fieldsights/465-geontologies-of-the-otherwise

Rodrigues de Mello, R., Marini, F. \& Gabassa, V. (2012). Comunidades de aprendizagem: outra escola é possível. São Carlos: Universidade Federal de São Carlos.
Román, A., Barton, J., Bustos, B. \& Salazar, A. (2015). Revolución salmonera: paradojas y transformaciones territoriales en Chiloé. Santiago: RIL, Instituto de Estudios Urbanos y Territoriales-Universidad Católica.

Rozzi, R., Anderson, C., Pizarro, C., Massardo, F., Medina, Y., Mansilla, A., Kennedy, J., Ojeda, J., Contador, T., Morales, V., Moses, K., Poole, A., Armesto, J. \& Kalin, M. (2010). Filosofía ambiental de campo y conservación biocultural en el Parque Etnobotánico Omora: aproximaciones metodológicas para ampliar los modos de integrar el componente social («S») en Sitios de Estudios Socio-Ecológicos a Largo Plazo (SESELP). Revista Chilena de Historia Natural, (83), 27-68.

Santos, P., Almeida, B. \& Henning, P. (2017). Livro Verde Ciência aberta e dados abertos: mapeamento e análise de políticas, infraestruturas e estratégias em perspectiva nacional e internacional. Río de Janeiro: Fiocruz.

Simões, E. (2015). Territórios em disputa: do impasse ao jogo compartilhado entre técnicos e residentes - Parque Estadual da Serra do Mar. São Paulo: Annablume, Fundação de Amparo à Pesquisa do Estado de São Paulo.

Skewes, J. C., Álvarez, R. \& Navarro, M. (2012). Usos consuetudinarios, conflictos actuales y conservación en el borde costero de Chiloé insular. Revista Magallania, 40(1), 109-125. doi: http://dx.doi.org/10.4067/S0718-22442012000100006

Tecklin, D. (2016). La apropiación de la costa chilena: ecología política de los derechos privados en torno al mayor recurso público del país. En Prieto, M., Bustos, B. \& Barton, J. (Eds.), Ecología política en Chile: naturaleza, propiedad, conocimiento y poder (pp. 121-142). Santiago: Editorial Universitaria.

Tsing, A. (2015). The Mushroom at the End of the World: On the Possibility of Life in Capitalist Ruins. New Jersey: Princeton University Press.

Tsing, A., Swanson, H., Gan, E. \& Bubandt, N. (2017). The Arts of Living on a Damaged Planet. Minneapolis: University of Minnesota Press.

Viveiros de Castro, E. (2002). A insconstância da alma selvagem. São Paulo: CosacNaify.

(2004). The Transformation of Objects into Subjects in Amerindian Ontologies. Common Knowledge, 10(3), 463-484.

Wang, S. \& Fu, B. (2013). Trade-offs between Forest Ecosystem Services. Forest Policies and Economics, (26), 145-146. doi: http:// dx.doi.org/10.1016/j.forpol.2012.07.014

Williams, R. (2001). El campo y la ciudad. Buenos Aires: Paidós. 